\title{
INVENTARISASI TUMBUHAN PAKU (Pteridophyta) DI PERKEBUNAN PT BINA SAINS CEMERLANG KABUPATEN MUSI RAWAS
}

\author{
Wahyuningsih ${ }^{1}$, Merti Triyanti ${ }^{2}$, Sepriyaningsih ${ }^{3}$ \\ 1,2,3 STKIP PGRI Lubuklinggau, Jl. Mayor Toha Kel. Air Kuti, Lubuklinggau 31626, Indonesia \\ *Corresponding author, e-mail: mertitriyanti28@gmail.com
}

\begin{abstract}
This study aims to determine the type of pteridophyta, abiotic factors and the benefits of pteridophyta in PT Bina Sains Cemerlang Plantation, Musi Rawas Regency. The research method used is descriptive qualitative. Data collection techniques in this study were carried out by surveying the research location and then determining the place by using purposive sampling technique. Data analysis techniques with the steps of the methods of observation, documentation, taking pteridophyta and identification. The results of the study of the inventory of pteridophyta at PT Bina Sains Cemerlang Musi Rawas Regency there are 9 families, 19 species, namely Asplenium nidus, Dyplazium pynocarpon, Davallia denticulate, Davallia solida, Nephrolepis biserrata, Nephrolepis cordifolia, Nephrolepis exisplis, Nephrolepis exis. Stenochlaenae palustris, Gleichenia linearis, Lycopodium cernuum,Diplazium esculentum, Drymoglossum piloselloides, Drynaria quercifolia, Phymatosorus scolopendria, Pteris biaurita, Vazaria esculentum, Drymoglossum piloselloides, Drynaria quercifolia, Phymatosorus scolopendria, Pteris biaurita, Vittaria lineculum, Drymoglossum piloselloides, Drynaria quercifolia, Phymatosorus scolopendria, Pteris biaurita, Vittaria lineate, Drymoglossum piloselloides, Drynaria quercifolia, Phymatosorus scolopendria, Pteris biaurita, Selaginella plenary. Soil moisture $8 \%-68 \%$ and soil pH of 7.08-8.00. Benefits of pteridophyta in PT Bina Sains Cemerlang Plantation, Musi Rawas Regency as ornamental plants and as vegetables.
\end{abstract}

Keywords: Inventory, Pteridophyta, PT Bina Sains Cemerlang

\section{PENDAHULUAN}

Tumbuhan adalah salah satu golongan makhluk hidup bersel banyak yang ada di muka bumi. Tumbuhan memiliki bagian tubuh yang dapat dibedakan menjadi akar, batang, dan daun. Tumbuhan memiliki ukuran yang sangat beragam, mulai dari yang berukuran kecil yang tidak memiliki kayu hingga pohon besar dan sangat tinggi yang usianya dapat mencapai ratusan tahun. Jenis tumbuhan ada yang dapat dimakan dan ada juga yang tidak dapat dimakan karena beracun atau berduri (Fitriana, 2008).

Salah satu kelompok tumbuhan yang tertua yang masih dapat dijumpai didaratan adalah tumbuhan paku (Pteridophyta) yang mencangkup lebih dari 9.000 spesies (Tjitrosomo, 2010). Tumbuhan paku tersebar di seluruh bagian dunia, kecuali daerah bersalju dan daerah kering (gurun). Sebagian besar tumbuh didaerah tropika basah yang lembab. Total spesies yang diketahui hampir 10.000 (diperkirakan 3000 di antaranya tumbuh di Indonesia). Tumbuhan paku cenderung tidak tahan dengan kondisi kering atau air yang terbatas (Mardiastutik, 2013). Tumbuhan paku (Pteridophyta) merupakan kelompok tumbuhan berpembuluh yang paling sederhana dan digolongkan dalam Cormophyta berspora yang telah memiliki pembuluh angkut. Tumbuhan paku (Pteridophyta) dapat hidup epifit, higrofit, hidrofit, dan hidup pada 
sisa-sisa tumbuhan lain (Wijana, 2014). Pertumbuhan dan perkembangan tumbuhan dipengaruhi oleh berbagai faktor-faktor yang dapat dibedakan menjadi dua, yaitu faktor dalam (internal) yaitu gen dan hormon. Sedangkan faktor luar (eksternal) yaitu air, mineral, cahaya matahari, suhu, dan kelembapan (Saktyowati, 2010).

Tumbuhan paku cukup banyak, ada beberapa jenis tumbuhan paku salah satunya yaitu Asplenium nidus dimanfaatkan sebagai tanaman hias, dan juga dapat dijumpai tumbuhan paku (Pteridophyta) yang tumbuh di batang kelapa sawit, pohon, ditanah dan disepanjang pinggir jalan. Salah satu tempat yang dijadikan sebagai lokasi penelitian tumbuhan paku (Pteridophyta) yaitu di Perkebunan PT Bina Sains Cemerlang. Perkebunan ini memiliki luas sekitar 6.513 Ha. PT Bina Sains Cemerlang adalah salah satu Perusahaan yang bergerak dalam bidang perkebunan kelapa sawit, dimana hasil yang telah dipanen diproduksi sendiri oleh PT Bina Sains Cemerlang yang terletak di desa Sungai Pinang Kecamatan Muara Lakitan Kabupaten Musi Rawas. Perkebunan PT Bina Sains Cemerlang merupakan salah satu daerah yang banyak terdapat tumbuhan paku.

Berdasarkan hasil observasi di Perkebunan PT Bina Sains Cemerlang bahwa tumbuhan paku cukup banyak. Hasil yang diperoleh melalui observasi tersebut bahwa ada beberapa jenis tumbuhan paku salah satunya yaitu Asplenium nidus dimanfaatkan sebagai tanaman hias, dan juga dapat dijumpai tumbuhan paku (Pteridophyta) yang tumbuh di batang kelapa sawit, pohon, ditanah dan disepanjang pinggir jalan. Hasil observasi yang dilakukan di Perkebunan PT Bina Sains Cemerlang Kabupaten Musi Rawas terdapat jenis-jenis tumbuhan paku-pakuan yang belum di identifikasikan dan belum ada penelitian sebelumnya yang melakukan penelitian tentang jenis-jenis tumbuhan paku (Pteridophyta) di Perkebunan PT Bina Sains Cemerlang Kabupaten Musi Rawas.

\section{METODE}

\section{Alat dan Bahan}

Alat yang digunakan dalam penelitian ini adalah sebagai berikut: Buku referensi tumbuhan paku (Pteridophyta), kamera, alat tulis, pisau, gunting, koran, karton, kertas label, isolasi, botol semprot, Soil tester, Thermometer, Hygrometer, plastik, plastik bening, benang, jarum, air, peta lokasi, alkohol $70 \%$ dan semua tumbuhan paku (Pteridophyta).

\section{Prosedur Penelitian}

Prosedur penelitian ini adalah diawali dengan kegiatan observasi yang bertujuan untuk mendapatkan data awal mengenai tumbuhan paku (Pteridophyta) di Perkebunan PT Bina Sains Cemerlang Kabupten Musi Rawas dapat dilihat dengan keadaan lokasi yang akan dijadikan objek penelitian serta melihat beberapa habitatnya. Selanjutnya melakukan pengambilan sampel dan pembuatan herbarium kering yaitu: tumbuhan paku (Pteridophyta) diambil terdiri dari akar, batang, daun dan spora dikoleksi. Kemudian dimasukkan kedalam kantong plastik putih disemprotkan dengan alkohol 70\% dan label yang berisi keterangan nomor spesies, nama lokal, lokasi dan nama tumbuhan paku (Pteridophyta). Tumbuhan tersebut diletakkan diatas koran dan disemprotkan alkohol 70\% kemudian ditutup dengan koran dengan isolasi. Herbarium kering, tumbuhan paku (Pteridophyta) dianginkan dan disemprot lagi dengan menggunakan alkohol 70\%. Herbarium yang telah kering langsung dipindahkan keatas karton tebal, kemudian diisolasi dan dijahit, serta diberi keterangan kemudian diidentifikasi (Purnawati dkk, 2014). Selanjutnya adalah 
mengukur faktor abiotik yang meliputi mengukur suhu udara menggunakan alat berupa Termometer, untuk mengukur kelembapan tanah menggunakan Hygrometer, dan mengukur $\mathrm{pH}$ tanah menggunakan alat soil tester.

\section{Analisis Data}

Penelitian ini dianalisis data yang diperoleh dari jenis, faktor abiotik dan manfaat tumbuhan paku (Pteridophyta) lalu diidentifikasi dengan mengacu pada buku panduan Van Steenis (2013), Rina Fitriana (2008), buku Dian Oky Saktyowati (2016), Wiwik Endang Mardiastutik (2013), Siti Sutarmi Tjitrosomo (2010) dan Nyoman Wijaya (2014).

\section{HASIL DAN PEMBAHASAN}

Berdasarkan hasil penelitian yang dilakukan peneliti pada tanggal 15 Maret - 10 April 2019 di PT Bina Sains Cemerlang Kabupaten Musi Rawas, peneliti menemukan 9 famili tumbuhan paku (Pteridophyta) yaitu Aspleniaceae, Blechnaceae, Davalliaceae, Dryopteridaceae, Gleicheniaceae, Lycopodiaceae, Polypodiaceae, Pteridaceae, Selaginellaceae dengan 19 spesies tumbuhan paku (Pteridophyta). Faktor abiotik yang dapat mempengaruhi pertumbuhan paku berbeda-beda karena sesuai dengan kebutuhannya yaitu suhu udara $31^{\circ} \mathrm{C}-33^{\circ} \mathrm{C}$ sedangkan kelembaban tanah yaitu $8 \%$ $68 \%$ dan pH tanah berkisar 7,08-8,00.

Berdasarkan hasil observasi diketahui bahwa jenis tumbuhan paku (Pteridophyta) yang ditemukan di Perkebunan PT Bina Sains Cemerlang Kabupaten Musi Rawas kebanyakan tidak dimanfaatkan, ada satu tumbuhan paku yang dikonsumsi masyarakat sebagai bahan makanan yaitu Diplazium esculantum dan ada yang digunakan sebagai tanaman hias yaitu Asplenium nidus.

Tumbuhan paku (Pteridophyta) yang paling banyak di temukan di kawasan Perkebunan PT Bina Sains Cemerlang Kabupaten Musi Rawas adalah famili Dryopteridaceae sebanyak 6 spesies yaitu Nephrolepis biserrata, Nephrolepis cordifolia, Nephrolepis exaltata, Nephrolepis sp., Ploecnemia irregularis dan Stenochlaenae palustris. Famili ini termasuk golongan jenis paku terestrial. Habitatnya ditempat yang lembab dengan akar berbentuk serabut, batang berwarna hijau dan sedikit berbulu, tingginya mencapai $150 \mathrm{~cm}$. Daun berbentuk majemuk dengan lebarnya mencapai $45 \mathrm{~cm}$, panjang dan lebar anak daun $25 \mathrm{~cm}$ dan $3 \mathrm{~cm}$. Dalam satu tangkai, biasanya daun berjumlah daun 46 helai dan anak daun berjumlah 62 helai. Pada permukaan daun bagian atas berwarna hijau tua dan pada permukaan bawah berwarna hijau muda. Saat muda daun berwarna merah diselimuti oleh benangbenang halus keperakan. Daun bertekstur agak keras dengan bentuk persegi. Sorus berada di permukaan daun (Ceri, dkk, 2014).

Nephrolepis biserrata hidup pada $\mathrm{pH}$ tanah 8,00 kelembaban tanah 10\% dan suhu udara $32^{\circ} \mathrm{C}$ hidup pada suhu lingkungan yang tinggi (Permana, 2017). Nephrolepis biserrata hidup pada $\mathrm{pH}$ tanah 4,2-4,4 bersifat asam sedangkan kelembaban tanah 7,2-9\% (Permana 2017). Nephrolepis cordifolia hidup pada $\mathrm{pH}$ tanah 7,08 kelembaban tanah $9 \%$ dan suhu udara $33^{\circ} \mathrm{C}$. Menurut Riastuti dkk (2018:67) Nephrolepis cordifolia hidup pada suhu lingkungan berkisar antara $28^{\circ} \mathrm{C}$ $31^{\circ} \mathrm{C}$ yang berarti suhu relatif normal untuk pertumbuhan paku dan $\mathrm{pH}$ tanah 6,18 yang berarti asam. Menurut Permana (2017) kelembaban tanah sebesar 8,9\%-9\%. Nephrolepis exaltata hidup pada $\mathrm{pH}$ tanah 7,08 kelembaban tanah 23\% dan suhu udara $32^{\circ} \mathrm{C}$. Menurut Riastuti dkk (2018) Nephrolepis exaltata hidup pada suhu lingkungan berkisar antara $28^{\circ} \mathrm{C}-31^{\circ} \mathrm{C}$ yang berarti suhu relatif normal untuk 
pertumbuhan paku dan pH tanah 6,18 yang berarti asam. Menurut Sari (2017) hidup pada kelembaban tanah 1-2,5. Neprolepis sp hidup pada $\mathrm{pH}$ tanah 7,08 kelembaban tanah $15 \%$ dan suhu udara $31^{\circ} \mathrm{C}$. Menurut Darma dkk (2018:43) Nephrolepis sp hidup pada suhu lingkungan berkisar antara $20,46^{\circ} \mathrm{C}$, pH tanah $6,0 \mathrm{~K}$ dan kelembaban tanah $29,12 \%$. Ploecnemia irregularis hidup pada $\mathrm{pH}$ tanah 7,09 sedangkan suhu lingkungan $32^{\circ} \mathrm{C}$ dan kelembaban tanah 19\%. Menurut Darma dkk (2018) Ploecnemia irregularis hidup pada suhu lingkungan berkisar antara $28^{\circ} \mathrm{C}-31^{\circ} \mathrm{C}$ yang berarti suhu relatif normal untuk pertumbuhan paku, $\mathrm{pH}$ tanah 6,16 yang berarti asam. Menurut Sari (2017) Ploecnemia irregularis hidup pada kelembaban tanah 1-2\%. Stenochlaenae palustris hidup pada $\mathrm{pH}$ tanah7,08 sedangkan menurut Riastuti dkk (2018) suhu lingkungan $31^{\circ} \mathrm{C}$ yang berarti suhu relatif normal untuk pertumbuhan paku dan kelembaban tanah 12\%. Menurut Ridianingsih dkk (2017) Stenochlaenae palustris hidup pada $\mathrm{pH}$ tanah 6,4-6,5 sedangkan kelembaban tanah $20 \%$.

Famili Polypodiaceae juga ditemukan sebanyak 4 spesies yaitu Diplazium esculentum, Drymoglossum piloselloides, Drynaria quercifolia, dan Phymatosorus scolopendria. Diplazium esculentum hidup pada $\mathrm{pH}$ tanah yaitu 7,09 kelembaban tanah 68\% dan suhu lingkungan $32^{\circ} \mathrm{C}$. Menurut Syafrudin dkk (2016) Diplazium esculentum hidup pada suhu $28^{\circ} \mathrm{C}-31^{\circ} \mathrm{C}$ yang berarti suhu relatif normal. Menurut Kurniawati dkk (2016) Diplazium esculentum hidup pada $\mathrm{pH}$ tanah 7,5 sedangkan kelembaban tanah 30\%-40\%. Drymoglossum piloselloides hidup pada $\mathrm{pH}$ tanah yaitu 7,08 sedangkan kelembaban tanah 8\% dan Menurut Apriyanti dkk (2017) suhu lingkungan $32^{\circ} \mathrm{C}$ yang berarti suhu relatif normal untuk pertumbuhan paku. Menurut Imaniar dkk (2017) Drymoglossum piloselloides hidup pada $\mathrm{pH}$ tanah 6,2-6,7 sedangkan kelembaban tanah 47,53. Drynaria quercifolia hidup pada $\mathrm{pH}$ tanah 7,09 kelembaban tanah $12 \%$, suhu lingkungan $32^{\circ} \mathrm{C}$. Menurut Permana (2017:66) Drynaria quercifolia hidup pada suhu $28^{\circ} \mathrm{C}-30^{\circ} \mathrm{C}$. Menurut Kurniawati dkk (2016) Drynaria quercifolia hidup pada $\mathrm{pH}$ tanah 7,5-8 kelembaban tanah 20\%-40\%. Phymatosorus scolopendria hidup pada pH tanah yaitu 7,09 sedangkan kelembaban tanah $12 \%$ dan hidup pada suhu lingkungan $31^{\circ} \mathrm{C}$. Menurut Riastuti dkk (2018) Phymatosorus scolopendria hidup pada $\mathrm{pH}$ tanah 6,18 dan kelembaban tanah 20\%-40\%.

Famili Davalliaceae terdiri dari 2 spesies yaitu Davallia denticulate dan Davallia solida. Davallia denticulate hidup pada $\mathrm{pH}$ tanah 7,09 sedangkan kelembaban tanah $13 \%$ dan suhu udara sekitar $33^{\circ} \mathrm{C}$. Menurut Riastuti dkk (2018) Davallia denticulate hidup pada suhu $28^{\circ} \mathrm{C}-31^{\circ} \mathrm{C}$ yang berarti suhu relatif normal untuk pertumbuhan paku. Menurut Kurniawati dkk (2016), Davallia denticulate hidup pada pH tanah sekitar 7,9-8 sedangkan kelembapan tanah mencapai 20\%-40\%.

Famili Selaginellaceae sebanyak 2 spesies yaitu Selaginellaceae plana dan Selaginellaceae wildenowii. Selaginella plana hidup pada $\mathrm{pH}$ tanah yaitu 7,08 sedangkan kelembaban tanah $10 \%$ dan suhu lingkungan $32^{\circ} \mathrm{C}$. Menurut Apriyanti dkk (2017) Selaginella plana hidup pada suhu lingkungan $24^{\circ} \mathrm{C}-32^{\circ} \mathrm{C}$. Menurut Riastuti dkk (2018) hidup pada pH tanah 6,18 yang berarti asam. Sedangkan kelembaban tanah 8,5\%-9\% yang bersifat basah (Permana, 2017).

Famili Pteridaceae terdiri 1 spesies yaitu Pteris biaurita. Pteris biaurita hidup pada $\mathrm{pH}$ tanah yaitu 7,08 sedangkan kelembaban tanah $9 \%$ dan suhu lingkungan $32^{\circ} \mathrm{C}$. Menurut Riastuti dkk (2018) Pteris biaurita hidup pada suhu lingkungan $28^{\circ} \mathrm{C}$ $31^{\circ} \mathrm{C}$ yang berarti suhu relatif normal untuk pertumbuhan paku dan hidup pada $\mathrm{pH}$ tanah 6,16 yang berarti asam. kelembaban tanah 1,5 yang bersifat basa (Sari, 2017).

Famili Aspleniaceae memiliki 1 spesies yaitu Asplenium nidus. Asplenium nidus ditemukan pada pH tanah 6,12 yaitu relatif normal (Permana, 2017). Suhu udara 
sekitar $31^{\circ} \mathrm{C}$ yang berarti suhu relatif normal untuk pertumbuhan paku (Riastuti dkk, 2018:58). Kelembaban tanah 13\%. Menurut Ridianingsih dkk (2017) kelembapan tanah pada tumbuhan paku Asplenium nidus yaitu $20 \%$.

Famili Gleicheniaceae memiliki 1 spesies yaitu Gleichenia linearis hidup pada $\mathrm{pH}$ tanah 8,00 sedangkan kelembaban tanah $9 \%$ dan suhu lingkungan $31^{\circ} \mathrm{C}$ yang berarti suhu relatif normal untuk pertumbuhan paku (Riastuti dkk, 2018). Menurut Kurniawati dkk (2016) Gleichenia linearis hidup pada $\mathrm{pH}$ tanah 7,5 sedangkan kelembaban tanah 20\%-40\%. Gleichenia linearis mempunyai percabangan khusus yaitu tiap-tiap cabang bercabang dua dan masing-masing cabang akan bercabang dua lagi. Akar berwarna hijau dan sporangium terdapat pada setiap Pina (anak daun) dan penyebarannya terbatas disepanjang daun (Elsifa dkk, 2019).

Famili Lycopodiaceae memiliki 1 spesies yaitu Lycopodium cernuum hidup pada $\mathrm{pH}$ tanah 7,09 sedangkan kelembaban tanah $29 \%$ dan suhu lingkungan $32^{\circ} \mathrm{C}$. Menurut Syafrudin dkk (2016) Lycopodium cernuum hidup pada suhu lingkungan berkisar antara $19^{\circ} \mathrm{C}$ yang berarti suhu relatif normal untuk pertumbuhan pakudan kelembaban tanah 90\%. Famili Blechnaceae memiliki 1 spesies yaitu Dyplazium pynocarpon hidup pada $\mathrm{pH}$ tanah 7,09 sedangkan kelembaban tanah 9\% dan suhu udara sekitar $32^{\circ} \mathrm{C}$.

Ada beberapa tumbuhan paku (Pteridophyta) yang hanya ditemukan, dikarenakan perbedaan suhu lingkungan, kelembaban tanah, dan $\mathrm{pH}$ tanah. Tumbuhan paku (Pteridophyta) menyukai temperatur sejuk dan kelembaban yang tinggi serta $\mathrm{pH}$ tanah berada pada kisaran 6-7. Apabila $\mathrm{pH}$ tanah $<7$ adalah asam dan apabila $\mathrm{pH}$ tanah $>7$ adalah basa (Permana, 2017). Faktor abiotik yang berpengaruh bagi pertumbuhan tumbuhan paku (Pteridophyta) antara lain suhu lingkungan, kelembaban tanah, $\mathrm{pH}$ tanah, intensitas cahaya, dan ketinggian. Parameter yang diukur dalam penelitian ini adalah suhu lingkungan, $\mathrm{pH}$ tanah dan kelembaban tanah. Menurut Permana (2017) menyatakan bahwa pengaruh $\mathrm{pH}$ tanah terhadap penyerapan zat hara dan pertumbuhan meliputi pengaruh dari zat beracun dan kelembaban zat hara. Paku yang hidup didaerah berbatu membutuhkan $\mathrm{pH}$ yang lebih basa yaitu 7-8. Sebagian besar tumbuhan paku (Pteridophyta) yang ditemukan di Perkebunan PT Bina Sains Cemerlang tumbuh subur pada tanah dengan pH basa antara 7,08-8,00.

Selain faktor dari pH tanah juga ada suhu berperan dalam pertumbuhan paku. Tumbuhan paku (Pteridophyta) yang tumbuh dikawasan Perkebunan PT Bina Sains Cemerlang tumbuh dengan kisaran suhu $31^{\circ} \mathrm{C}-33^{\circ} \mathrm{C}$. Menurut Permana (2017) menyatakan bahwa pada suhu yang berkisar antara $30^{\circ} \mathrm{C}-33^{\circ} \mathrm{C}$ tidak terlalu banyak tumbuhan paku (Pteridophyta).

Selain itu terdapat kelembapan tanah. Imaniar dkk (2017), menyatakan bahwa semakin bertambahnya ketinggian suhu udara dan kelembapan dilokasi penelitian semakin menurun. Tingkat kelembaban 3\% ialah persentase terendah yang masih dapat ditoleransi oleh tumbuhan paku (Pteridophyta) untuk pertumbuhannya. Kelembapan relatif yang baik bagi pertumbuhan tumbuhan paku (Pteridophyta) pada umumnya berkisar antara 6-8\% bahkan bisa lebih dari itu. Kelembaban tanah berpengaruh terhadap penyerapan unsur hara dan laju pertumbuhan (Permana, 2017).

Tumbuhan paku (Pteridophyta) memiliki tingkat toleransi tertentu terhadap kondisi lingkungannya agar tetap hidup dan berkembang. Jika kondisi lingkungan berubah melebihi tingkat toleransinya, maka akan mengakibatkan kemusnahan tumbuhan dari habitat tersebut (Permana, 2017). Berdasarkan hasil penelitian 
perkembangan tumbuhan paku (Pteridophyta) lebih menyukai $\mathrm{pH}$ tanah yang basa, suhu lingkungan yang relatif normal, dan kelembaban tanah yang relatif rendah. Walaupun ada beberapa paku yang dapat hidup pada suhu yang tinggi dan kelembaban tanah yang relatif tinggi maupun rendah dapat dikatakan bahwa jenisjenis tumbuhan paku yang hanya dapat ditemukan pada area tertentu karena memiliki daya toleransi yang rendah terhadap kondisi lingkungan.

\section{SIMPULAN}

Berdasarkan hasil penelitian disimpukan bahwa tumbuhan paku (Pteridophyta) yang telah di temukan di Perkebunan PT Bina Sains Cemerlang Kabupaten Musi Rawas yaitu 9 famili dan 19 spesies yang terdiri dari Asplenium nidus, Dyplazium pynocarpon, Davallia denticulate, Davallia solida, Nephrolepis biserrata, Nephrolepis cordifolia, Nephrolepis exaltata, Nephrolepis sp., Ploecnemia irregularis, Stenochlaenae palustris, Gleichenia linearis, Lycopodium cernuum, Diplazium esculentum, Drymoglossum piloselloides, Drynaria quercifolia, Phymatosorus scolopendria, Pteris biaurita, Selaginella plana, dan Selaginella wildenowii. Faktor abiotik pada lokasi penelitian yaitu suhu udara yaitu $31^{\circ} \mathrm{C}-33^{\circ} \mathrm{C}$ relatif normal, kelembapan tanah yaitu 8\%-68\% merupakan kelembaban yang baik untuk pertumbuhan paku, $\mathrm{pH}$ tanah berkisar 7,08-8,00 bersifat basa.

\section{REFERENSI}

Apriyanti, N., Santri, D.J., \& Madang, Kodri. (2017). Identifikasi Tumbuhan Paku (Pteridophyta) dan Kekerabatannya di Kawasan Wisata Air Terjun Curup Tenang Bedegung Kecamatan Tanjung Agung Kabupaten Muara Enim. Jurnal Pembelajaran Biologi. 5(2), 113-125.

Arini, D.I.D., \& Julianus, J. (2012). Keragaman Jenis Tumbuhan Paku (Pteridophyta) Di Cagar Alam Gunung Ambang Sulawesi Utara (The Pteridhopyta Diversity In Gunung Ambang Nature Reserve North Sulawesi). Jurnal BPK Manado, 2(1), 1740.

Ceri, B., Lovadi, I., \& Linda, R. (2014). Keanekaragaman Jenis Paku-pakuan (Pteridophyta) di Mangrove Muara Sungai Peniti Kecamatan Segedong Kabupaten Pontianak. Jurnal Protobiont, 3(2), 240-246.

Elsifa, A., Arisandy, A.D \& Harmoko. (2019). Eksplorasi Tumbuhan Paku (Pteridophyta) Di STL Ulu Terawas, Musi Rawas, Sumatera Selatan. BIOSFER: Jurnal Tadris Biologi, 10(1)47-55.

Fitriana, R. (2008). Mengenal Tumbuhan. Bandung: Putra Setia.

Imaniar, R., Pujiastuti, \& Murdiyah, S. (2017). Identifikasi Keanekaragaman Tumbuhan Paku di Kawasan Air Terjun Kapas Biru Kecamatan Pronojiwo Kabupaten Lumajang serta Pemanfaatannya sebagai Booklet. Jurnal Pendidikan Biologi, 6(3), 337-345.

Kurniawati, E., Wisantri, \& Rachmadiarti, F. Keanekaragaman Pteridophyta di Kawasan Hutan Wisata Air Terjun Girimanik Kabupaten Wonogiri. Jurnal LentraBio. 5(1), 74-78.

Mardiastutik, W. (2013). Mengenal Tumbuhan. Bekasi: Mitra Utama.

Purnawati, U., Turnip, M., \& Lovadi, I. (2014). Eksplorasi Paku-pakuan (Pteridophyta) di Cagar Alam Mandor Kabupaten Landak. Jurnal Protobiont, 3(2), 155-165.

Permana, N, E, P. (2017). Identifikasi keanekaragaman Divisi Pteridophyta (Paku) di kawasan Bukit Sulap Kota Lubuklinggau. Skripsi. Lubuklinggau: STKIP PGRI Lubuklinggau. 
Riastuti, R.D., Sepriyaningsih, \& Ernawati, D. (2018). Identifikasi Divisi Pteridophyta Di Kawasan Danau Aur Kabupaten Musi Rawas. Jurnal Pendidikan Biologi dan Sains (BIOEDUSAINS), 1(1), 52-70.

Ridianingsih, D.S., Pujiastuti, \& Hariani, S. A. (2017). Inventarisasi Tumbuhan Paku (Pteridophyta) di pos Rowobendo Ngagelan Taman Nasional Alas Purwo Kabupaten Banyuwangi. Jurnal Bioeksperimen, 3(2), 20-30.

Saktyowati, D. (2010). Mengenal Dunia Tumbuhan. Jakarta: Multazam Mulia Utama.

Sari, N.M. (2017). Identifikasi Keanekaragaman Divisi Pteridophyta (Paku) sebagai bahan pengembangan Booklet di kawasan Bukit Cogong Kabupaten Musi Rawas. Skripsi. STKIP PGRI Lubuklinggau.

Steenis, C.G.G.J.Van. (2013). Flora. Jakarta Timur: Balai Pustaka.

Syafrudin, Y., Haryati, T.S., \& Wiedarti, S. (2016). Keanekaragaman Dan Potensi Paku (Pteridophyta) Di Taman Nasional Gunung Gede Pangrango Cianjur (TNGGP). Jurnal Ekologia , 16(2), 24-31.

Tjitrosomo, S.S. (2010). Botani Umum 3. Bandung: Angkasa.

Wijana, N. (2014). Biologi dan Lingkungan. Yogyakarta: Plantaxia. 